\title{
Vibration Testing of the Pluto/New Horizons Radioisotope Thermoelectric Generator
}

\section{4th International Energy Conversion Engineering Conference}

\section{Charles D. Griffin}

June 2006

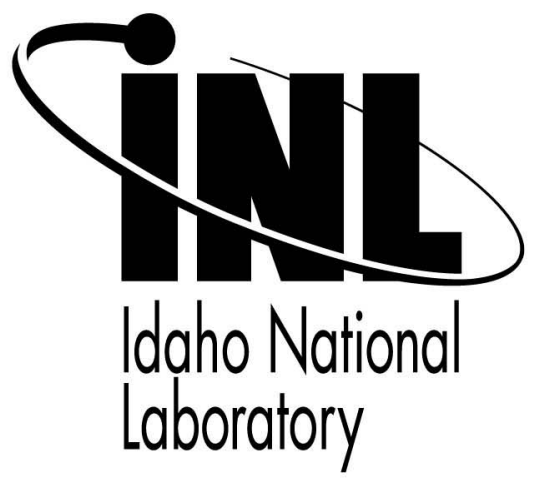

This is a preprint of a paper intended for publication in a journal or proceedings. Since changes may be made before publication, this preprint should not be cited or reproduced without permission of the author. This document was prepared as an account of work sponsored by an agency of the United States Government. Neither the United States Government nor any agency thereof, or any of their employees, makes any warranty, expressed or implied, or assumes any legal liability or responsibility for any third party's use, or the results of such use, of any information, apparatus, product or process disclosed in this report, or represents that its use by such third party would not infringe privately owned rights. The views expressed in this paper are not necessarily those of the United States Government or the sponsoring agency. 


\title{
Vibration Testing of the Pluto/New Horizons Radioisotope Thermoelectric Generator
}

\author{
Charles D. Griffin* \\ Idaho National Laboratory, Idaho Falls, Idaho, 83415
}

\begin{abstract}
The Radioisotope Thermoelectric Generator (RTG) for the Pluto/New Horizons spacecraft was subjected to a series of flight dynamic acceptance tests to demonstrate that it would perform successfully following launch. Seven RTGs of this type had been assembled and tested at Mound, Ohio, from 1984 to 1997. This paper chronicles major events in establishing a new vibration test laboratory at the Idaho National Laboratory and the dynamic testing during the Fall of 2005.
\end{abstract}

\section{Introduction}

The spacecraft for the Pluto/New Horizons mission launched on January 19, 2006, is powered by a General Purpose Heat Source Radioisotope Thermoelectric Generator (GPHS-RTG). The generator, the eighth in a series of converters (F8), uses heat sources containing Plutonium-238 to provide the 250 watts of electrical energy to power the on-board instrumentation. In 2002, the U.S. Department of Energy decided to relocate assembly and testing activities of RTGs from Mound, Ohio, to Scoville, Idaho. Following RTG assembly, a significant part of the flight acceptance tests involved subjecting the RTG to random and transient vibration environments on each of its two principal axes to confirm the workmanship of the assembly. Vibration testing for qualification of the design of the RTG had been completed over two decades earlier in 1984.

The task to establish a new vibration testing capability at the Idaho National Laboratory (INL) involved three major efforts - removal and relocation of the equipment from Ohio to Idaho, installation and testing of the equipment in the new facility, and testing of the F8 generator that would be used by the Pluto/New Horizons spacecraft.

\section{Removal and Relocation}

The task to remove and relocate the major pieces of equipment involved disconnection of electrical cabling, cooling water lines, plant instrument air lines, and hydraulic hoses that interconnected the equipment and Mound facility utilities. For example, Fig. 1 shows partial demolition at the base of the vibrator: cut water hoses, hydraulic fittings, yet to be removed air hoses, and the plate where the armature and field cables were disconnected. Ling Dynamics Systems Inc. (LDS), the original equipment manufacturer, provided technical assistance during the relocation and again during installation in Idaho.

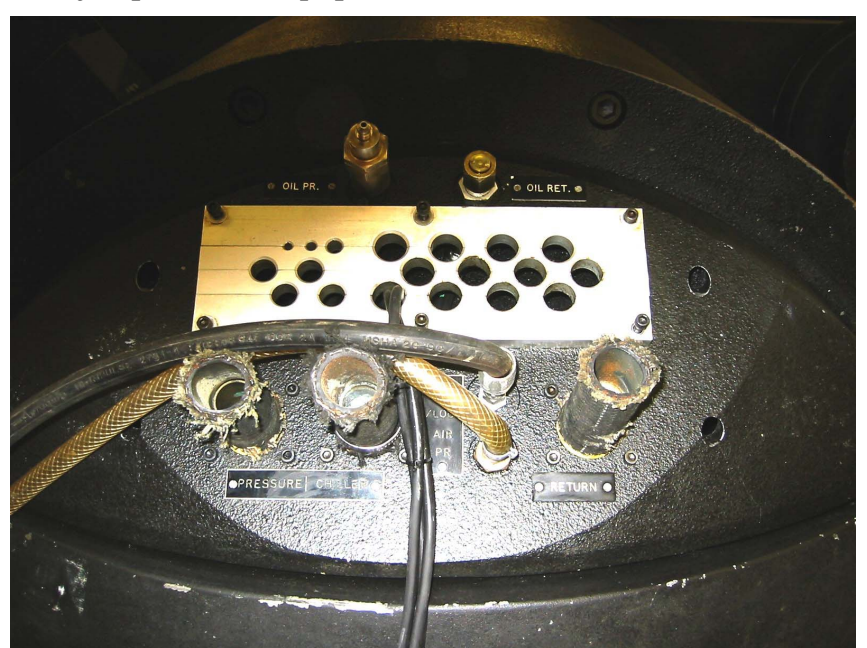

Figure 1. Demolished Vibrator Connections.

* Vibration Test Engineer, Radioisotope Power Systems, P. O. Box 1625/MS 6122, Idaho Falls, ID, 83415

1

American Institute of Aeronautics and Astronautics 


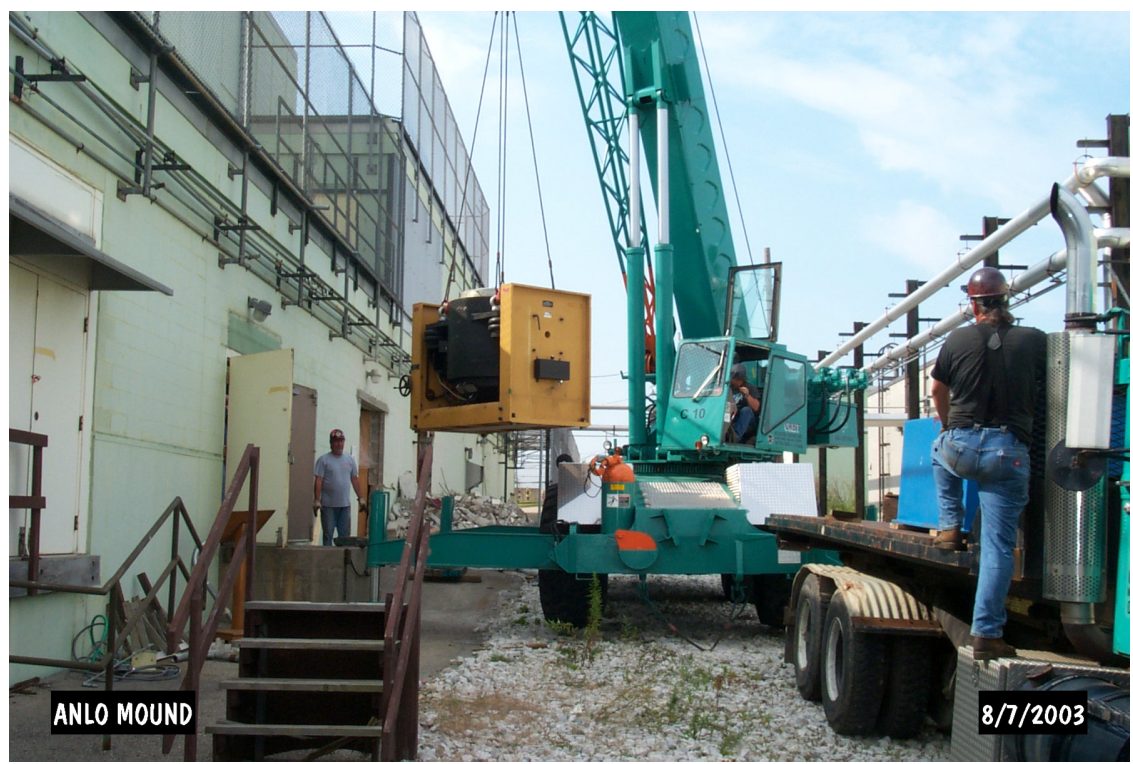

Figure 2. Vibrator Removal from Ohio.

Figure 2 shows removal of the 19,000 lb vibrator from the old facility in Ohio, and Fig. 3 shows the lift of when it was lowered through the roof of the new facility in Idaho eight months later.

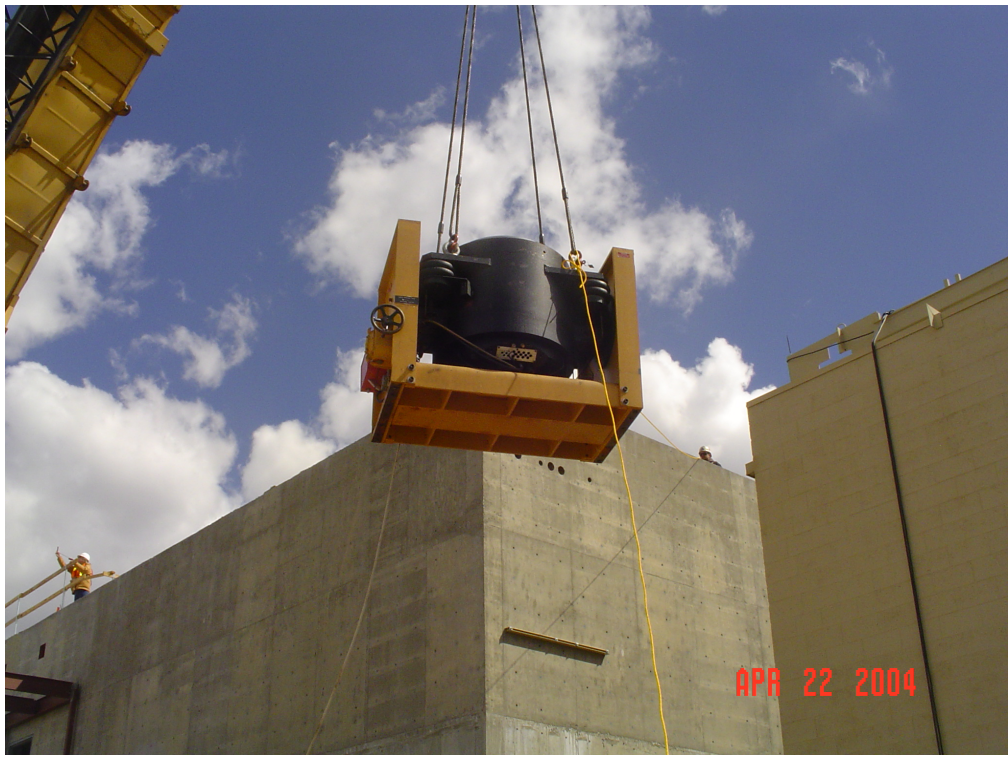

Figure 3. Vibrator Installation in Idaho.

As can be seen in the picture, the locating of major pieces of equipment occurred as the building was being constructed around it. Three major system components were handled in this manner; the isolation mass, vibrator, and slip table. The power amplifier, coupling transformer, and cooling unit/field power supply came into the building through the truck lock roll-up doors.

Construction was completed on the new Space and Security Power Systems Facility in July 2004, and followed by equipment setup and installation to support disassembly and recovery of Pu-238 heat sources for use in F8. During this period, the vibration equipment was installed in a parallel effort. 


\section{Installation}

The vibration equipment relocated from Mound was vintage 1981 and had not been operated since October 2002. During demolition, the LDS field service engineer recommended replacement of the slip table hydraulic unit, cooling unit, and field coil power supply. Because of the uncertain condition of the equipment, the vibration system engineer proceeded to:

- Procure a new cooling unit/field power supply;

- Repair and rebuild the slip table hydraulic unit;

- Replace all tubing, fittings, hoses, and wiring;

- Upgrade the controller and schedule training from the vendor, $\mathrm{m}+\mathrm{p}$ International Inc.;

- Send off the charge amplifiers, filters, accelerometers, and force transducers to their manufacturers for calibration and repair;. and

- Arrange for preventive maintenance of the vibrator.

Figure 4 shows removal of the vibrator top ring exposing the armature. The preventive maintenance

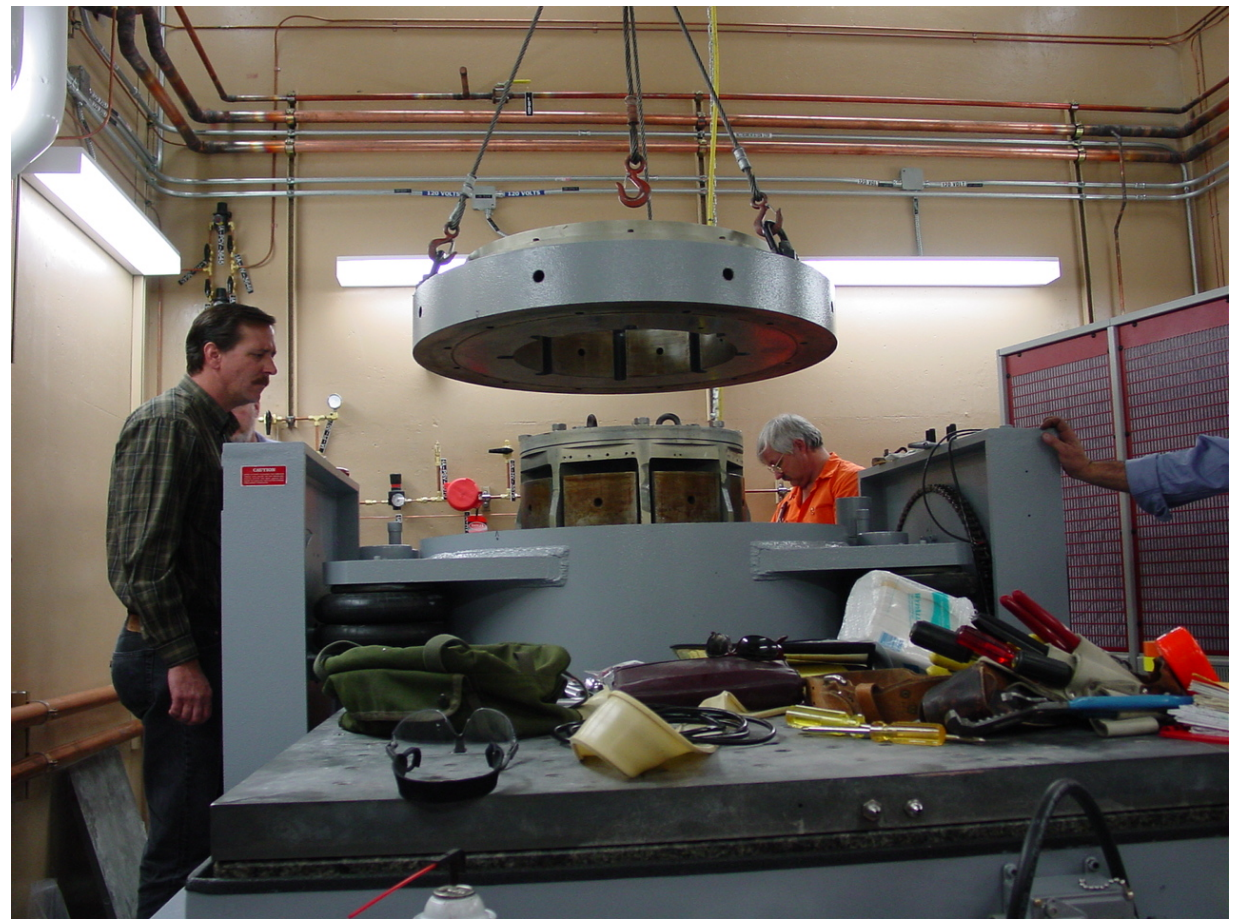

Figure 4. Vibrator Maintenance.

quickly became corrective maintenance when it was discovered that the armature cooling and power connections had corroded beyond use and the field coils exhibited evidence of overheating. A replacement armature had to be obtained from Great Britain, but a set of new field coils were available in the U.S.

Further mechanical problems presented themselves. The magnesium slip plate was sent off to a machine shop in California to have scratches removed from the mounting surface. The company that made the slip table in 1981 was no longer in business, and legacy parts had to be found to replace one of the three hydraulic bearings and the six pins used to connect the X-K driver bar between the vibrator and slip table that had been lost in the transfer of equipment from Ohio to Idaho.

During system checkout, a transient input signal to the amplifier blew output fuses in all 36 power modules. A sample of six modules returned to LDS for checkout indicated no damage to the modules beyond the opened fuses. As a corrective action, the instrument and equipment grounds were checked and upgraded. We also expedited delivery of the new controller and corrected (i.e., reduced) the maximum output setting from the testing profiles that had been used in Ohio.

We completed the installation, maintenance, and equipment testing in July of 2005. 


\section{Testing}

Following F8 fueling, a set of voltage, current, and resistance measurements were collected to form the pre-vibration test baseline power performance data. That data would again be collected post vibration testing along with the response accelerometer measurements to demonstrate acceptable test results. The vibration test sequence and environments are shown in Table 1.

Table 1.

Vibration Test Environments

\begin{tabular}{|c|c|c|c|c|}
\hline Test & Axis & \multicolumn{2}{|c|}{ Environment } & Duration \\
\hline 1 & $\mathrm{Y}$ & \multicolumn{2}{|c|}{ Sine Sweep } & 2 ctave nor minute \\
\hline 1 & $Y$ & $10-2000 \mathrm{~Hz}$ & $1 / 2 g$ & 2 octave per minute \\
\hline 2 & Y & $\begin{array}{r}20-72 \mathrm{~Hz}, \\
72-180 \mathrm{~Hz} \\
180-205 \mathrm{~Hz} \\
205-245 \mathrm{~Hz} \\
245-275 \mathrm{~Hz} \\
275-450 \mathrm{~Hz} \\
450-2000 \mathrm{~Hz} \\
\text { Overall }\end{array}$ & $\begin{array}{r} \\
+6 \mathrm{~dB} / \text { octave } \\
0.032 \mathrm{~g}^{2} / \mathrm{Hz} \\
-16 \mathrm{~dB} / \mathrm{octave}^{2} \\
0.016 \mathrm{~g}^{2} / \mathrm{Hz} \\
+18 \mathrm{~dB} / \text { octave }^{2} \\
0.032 \mathrm{~g}^{2} / \mathrm{Hz} \\
-6 \mathrm{~dB} / \text { octave } \\
4.78 \mathrm{~g}_{\mathrm{RMS}}\end{array}$ & 1 minute at $0 \mathrm{~dB}$ \\
\hline $3 a$ & Y & \multicolumn{2}{|c|}{ Transient } & 1 pulse at $0 \mathrm{~dB}$ \\
\hline $3 b$ & $\mathrm{Y}$ & \multicolumn{2}{|c|}{ Transient } & 1 pulse at $0 \mathrm{~dB}$ \\
\hline $3 c$ & Y & \multicolumn{2}{|c|}{ Transient } & 1 pulse at $0 \mathrm{~dB}$ \\
\hline $3 \mathrm{~d}$ & $\mathrm{Y}$ & \multicolumn{2}{|c|}{ Transient } & 1 pulse at $0 \mathrm{~dB}$ \\
\hline 4 & Y & \multicolumn{2}{|c|}{ Sine Sweep } & 2 octave per minute \\
\hline 5 & Z & \multicolumn{2}{|c|}{ Sine Sweep } & 2 octave per minute \\
\hline 6 & Z & $\begin{array}{r}20-51 \mathrm{~Hz} \\
51-176 \mathrm{~Hz} \\
176-192 \mathrm{~Hz} \\
192-240 \mathrm{~Hz} \\
240-256 \mathrm{~Hz} \\
256-352 \mathrm{~Hz} \\
352-380 \mathrm{~Hz} \\
380-450 \mathrm{~Hz} \\
450-2000 \mathrm{~Hz} \\
\text { Overall }\end{array}$ & $\begin{array}{r} \\
+6 \mathrm{~dB} / \text { octave } \\
0.016 \mathrm{~g}^{2} / \mathrm{Hz} \\
-24 \mathrm{~dB} / \text { octave }^{2} \\
0.008 \mathrm{~g}^{2} / \mathrm{Hz} \\
+10 \mathrm{~dB} / \text { octave }^{2} \\
0.01 \mathrm{~g}^{2} / \mathrm{Hz} \\
+46 \mathrm{~dB} / \text { octave }^{2} \\
0.032 \mathrm{~g}^{2} / \mathrm{Hz} \\
-6 \mathrm{~dB} / \text { octave } \\
4.22 \mathrm{~g}_{\text {RMs }} \\
\end{array}$ & 1 minute at $0 \mathrm{~dB}$ \\
\hline $7 \mathrm{a}$ & Z & \multicolumn{2}{|c|}{ Transient } & 1 pulse at $0 \mathrm{~dB}$ \\
\hline $7 b$ & Z & \multicolumn{2}{|c|}{ Transient } & 1 pulse at $0 \mathrm{~dB}$ \\
\hline $7 \mathrm{c}$ & Z & \multicolumn{2}{|c|}{ Transient } & 1 pulse at $0 \mathrm{~dB}$ \\
\hline $7 d$ & Z & \multicolumn{2}{|c|}{ Transient } & 1 pulse at $0 \mathrm{~dB}$ \\
\hline 8 & Z & \multicolumn{2}{|c|}{ Sine Sweep } & 2 octave per minute \\
\hline
\end{tabular}

During testing, the test team encountered several problems typical of vibration instrumentation and equipment. There were six controller initiated aborts. Aborts during the sine sweeps resulted from an inability to control the base accelerometers within $\forall 3 \mathrm{~dB}$ of the $1 / 2 \mathrm{~g}$ acceleration set point. The sine sweeps were completed by expanding the control bounds to $\forall 6 \mathrm{~dB}$ at the high end of the frequency range. Aborts during random testing resulted from noise and saturation of one of the response accelerometers at frequencies above the test range. Filtering and amplifier and cabling changes fixed these problems. 
Figure 5 is a picture of the RTG mounted for y-axis testing on the slip table. The vibrator, barely visible at the bottom of the picture has been rotated to a horizontal position and connected to the slip plate with the X-K driver bar. Low-noise cables connect the accelerometers and force transducers with the charge amplifiers and controller in the next room.

\section{Conclusion}

F8 passed the flight acceptance vibration tests. There was no damage or permanent distortion from the random and transient tests as determined by comparisons of pre and post test electrical performance data and because the response accelerometer results were similar in the pre and post test sine sweeps. For example, Fig. 6 is a comparison plot of the $1 / 2 \mathrm{~g}$ Y-axis sine sweeps (tests 1 and 4) of the accelerometer $\mathrm{Y}$-axis responses for the feature on the outboard end of the RTG known as the pressure relief device.

Note the three modes: the first at $48 \mathrm{~Hz}$, the second at

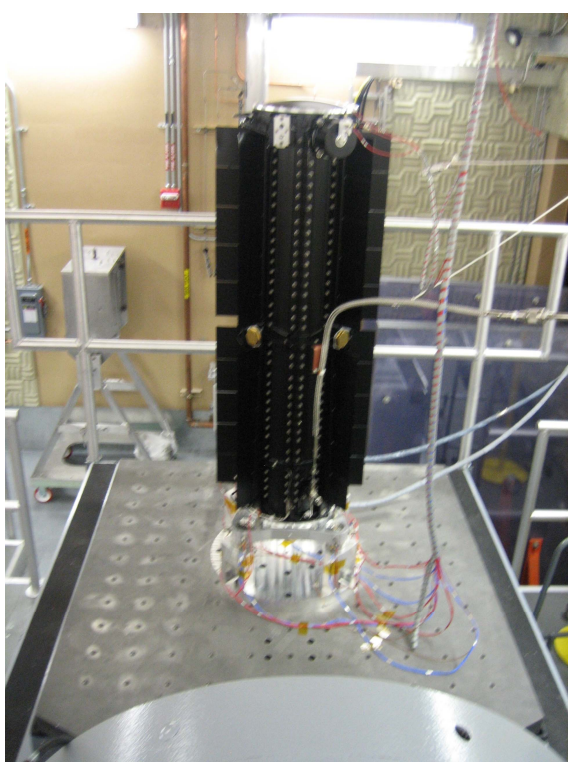

Figure 5. RTG Mounted for Y-axis Test. $220 \mathrm{~Hz}$, and the third at $370 \mathrm{~Hz}$. The response above 400 $\mathrm{Hz}$ reflects the difficulty in controlling the input applied to the RTG base caused by the mounting fixture.

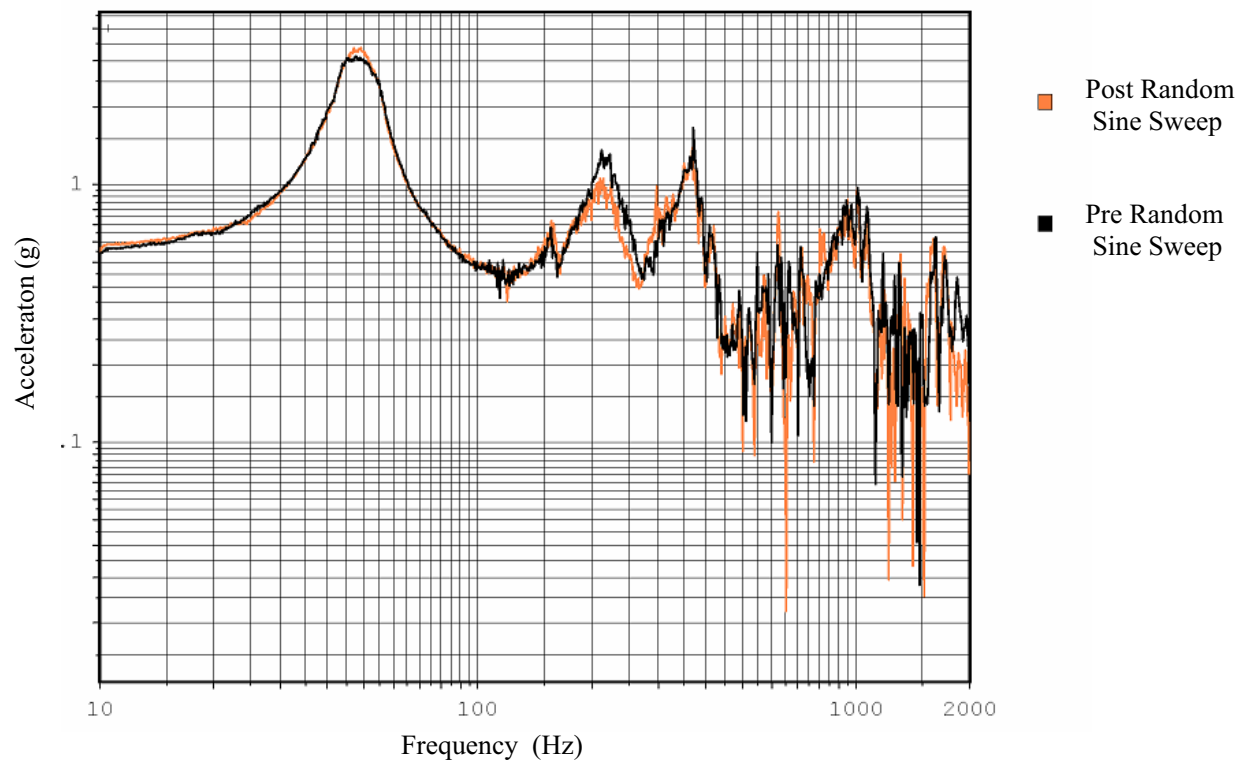

Figure 6. Comparison of Y-axis Sine Sweep Tests.

\section{Acknowledgments}

I would like to thank Curtis Albers of Ling Dynamic Systems Inc. and Jim Churchill of $\mathrm{m}+\mathrm{p}$ International Inc. for their expert assistance during equipment installation. I also thank Tim Hoye of Lockheed Martin and Bill Bohne of the USDOE for bridging the Ohio to Idaho gap, and finally, Dennis Hill of Lockheed Martin for being a dynamical dab hand.

Work supported by the U.S. Department of Energy, Office of Nuclear Energy under DOE Idaho Operations Office Contract DE-AC07-05ID14517. 